REGULAR ARTICLE

\title{
PHYTOCHEMICALS, ANTIOXIDANT AND ANTIMICROBIAL PROPERTIES OF Senna alata AND Senna tora LEAF EXTRACTS AGAINST BACTERIAL STRAINS CAUSING SKIN INFECTIONS
}

\author{
Nornasriq Akmal Nordin ${ }^{1}$, Nur Bainun Mohd Zin ${ }^{1}$, Nurul Farhana Fazilah', HelmiWasoh ${ }^{1,2}$, Arbakariya B. Ariff ${ }^{1,2}$, Murni Halim ${ }^{1,2 *}$ \\ Address (es): Anjana Thuduhenge Dona \\ ${ }^{1}$ Department of Bioprocess Technology, Faculty of Biotechnology and Biomolecular Sciences, Universiti Putra Malaysia, 43400 UPM Serdang, Selangor, Malaysia. \\ ${ }^{2}$ Bioprocessing and Biomanufacturing Research Centre, Faculty of Biotechnology and Biomolecular Sciences, Universiti Putra Malaysia, 43400 UPM Serdang, \\ Selangor, Malaysia.
}

*Corresponding author: murnihalim@upm.edu.my

\begin{abstract}
A study was carried out to screen for phytochemical constituents and assess the antioxidant and antimicrobial activities of Senna alata and Senna tora leaf extracts. The leaves were first dried at room temperature and $50^{\circ} \mathrm{C}$ in an oven prior to solvent extraction using ethanol and methanol. The in-vitro qualitative assays showed that both S. alata and S. tora leaf extracts contained bioactive and secondary metabolites components such as tannins, steroids, saponin, terpenoids, glycosides, flavonoids and phenols. The antioxidant activity and capacity test were carried out by conducting free radical of 2,2-diphenyl-1-picrylhydrazyl (DPPH) scavenging activity and Ferric reduction antioxidant plasma (FRAP) assays. Both assays showed $S$. tora leaf extract has higher antioxidant capacity than $S$. alata leaf extract. The efficacy of these leaf extracts were tested against skin pathogens through agar well diffusion method. S. alata extract showed an inhibition zone (1.15 - $1.59 \mathrm{~mm})$ against Pseudomonas aeruginosa while $S$. tora extracts exhibited a strong antimicrobial activity against $S$. epidermidis (inhibition zone of $12-16.94 \mathrm{~mm}$ ) followed by $P$. aeruginosa (inhibition zone of $1-1.59 \mathrm{~mm}$ ). Nonetheless, no inhibition zone was observed for $S$. aureus by both leaf extracts. The phytochemicals and antioxidant constituents as well as inhibitory potential on skin pathogens possessed by $S$. alata and $S$. tora leave highlighted their potential utilization in the development of natural drugs or cosmetics to treat skin related diseases or infections.
\end{abstract}

Keywords: Senna alata; Senna tora; skin infections; antioxidant; phytochemical; antimicrobial

\section{INTRODUCTION}

Medicinal plants have been used to treat various skin diseases for many decades. Medicinal plants may seem as old and conventional in treating skin disease but the result from using the medicinal plants mostly showed a positive result. Also, medicinal plant as natural remedies in treating skin disease typically will not give any harm on human external and internal body. Medicinal plants are being used in treating skin diseases like dermatitis, atopic dermatitis, eczema, furunculosis and other inflammatory diseases (Dawid, 2013).

Skin microflora can be pathogenic, commensalism or mutualism depending on the human's immune system (Cogen et al., 2008). The presence of skin flora could affect the behavior of the cell below the skin surface. For example, the ability for the skin to heal the inflammation after injury is reduced due to the presence of skin flora (Lai et al., 2004). According to Naik et al. (2015) bacteria presences inside the mice skin have the ability to affect the immune response. Quarter to half of nowadays medicine products derived from plants are being used as antimicrobial agents. This is due to the plants attribute that is enriched with secondary metabolites components like terpenoids, tannins, alkaloid, and flavonoids (Cowan, 1999). For instant, flavonoid constituents that are found in the medicinal plant can exhibit inhibitory effect against various viruses (Pengsuparp et al., 1995).

The development of plant-based product is rapidly increasing especially in many developing countries due to efficiency and ability to cure many diseases such as skin diseases (Oluduro and Omoboye, 2010). Besides, the effectiveness of the plants in curing diseases had been proven by our ancestor. For example, traditionally, Senna alata leaf is dried and grinded before it is mixed with kerosene and the mixture may then be applied to inflammation skin. In addition, in Africa, many of herbal medicines are being used as decoction in cold water, mix into food or alcohol to treat bacterial infections (Oluduro and Omoboye, 2010, He et al., 2015).

S. alata was originated from Ghana and Brazil but today, it is spread widely into Americas and all over Africa, and Nigeria (Adelowo and Oladeji, 2017). In Malaysia, the plant is known as "gelenggang". Therapeutic properties such as antibacterial, antimicrobial, antifungal and analgesic are reported for different parts of the plant. For instant, the $S$. alata leaf is claimed to have an efficiency to treat skin diseases in animal and man (Igoli et al., 2005). In addition, it is also has been reported for the treatments of constipation, haemorrhoids, intestinal parasitosis, inguinal hernia, blennorrhagia, diabetes and syphilis and proven to have the ability to cure ringworm (Abo et al., 2008).
Senna tora is generally distributed throughout India, Sri Lanka, West China and tropics. In Malaysia the plant is known as "ketepeng cina". Different parts of $S$. tora are known to possess various ailments by rural and tribal people due to its moist quality, sweet flavor and cooling property of herb, it acts on liver and large intestine channels, clear the heat and liver fire, and nourishing the large intestine (Kirtikar and Basu, 1998). In addition, the leaves and seeds are also useful in treatment of leprosy, ringworm, flatulence, bronchitis, cough and cardiac disorders (Jain and Patil, 2010).

The present study aimed to evaluate the phytochemical constituents, antioxidant properties and antimicrobial activity of $S$. alata and $S$. tora leaf extracts against skin diseases causing bacteria, Staphylococcus aureus, Staphylococcus epidermidis and Pseudomonas aeruginosa.

\section{MATERIALS AND METHODS}

\section{Collection and preparation of leaf extracts}

S. tora and S. alata leaves were collected from the Taman Pertanian, Universiti Putra Malaysia. First, the leaves were washed to remove undesired substances on the surface of the leaves and were allowed to dry. The leaves were then cut into small sizes and weighed. Two types of drying methods had been used to dry the leaves prior to solvent extraction step which were oven drying at $50^{\circ} \mathrm{C}$ for 8 hours and drying at room temperature for 3 days. After the drying procedures, the samples were grinded using a blender to get the desirable size. The samples in powder form were then kept in labeled bottles at $27^{\circ} \mathrm{C}$.

\section{Solvent Extraction Method}

A weight of $1 \mathrm{~g}$ of $S$. tora and $S$. alata leaves powdered samples were mixed with $100 \mathrm{~mL}$ of $95 \%(\mathrm{v} / \mathrm{v})$ ethanol or $80 \%(\mathrm{v} / \mathrm{v})$ methanol into conical flasks (Rabeta and Lin, 2015). The flasks were wrapped with an aluminium foil. The mixtures were shaken for overnight at $160 \mathrm{rpm}$ shaker (CERTOMAT BS-1, Boston Laboratory Equipement, MA), $27^{\circ} \mathrm{C}$. The mixtures were then centrifuged (Eppendorf, Eppendorf Asia Pacific, Malaysia) at $2500 \mathrm{rpm}$ for 30 minutes to obtain a clear solution. The solutions were stored at $4{ }^{\circ} \mathrm{C}$ until used. 


\section{Phytochemical analysis}

\section{Total flavonoids content}

Total flavonoids content was determined by using an aluminum colorimetric method and quercetin (QE) was used as a standard (Iqbal et al., 2015). $0.5 \mathrm{~mL}$ of extracts and quercetin were placed in test tubes. Then, $0.1 \mathrm{~mL}$ of $10 \% \mathrm{AlCl}_{3}$, $0.1 \mathrm{~mL}$ of $1 \mathrm{M}$ potassium acetate, $1.5 \mathrm{~mL}$ of $80 \%(\mathrm{v} / \mathrm{v})$ methanol and $2.8 \mathrm{~mL}$ of distilled water were placed in the test tubes. The tubes were then incubated at room temperature for 30 minutes. The absorbance was read by using a spectrophotometer (Libra S12, Biochrom, UK) at $415 \mathrm{~nm}$ and the total flavonoid content was expressed as $\mathrm{mg} \mathrm{QE} / \mathrm{g} \mathrm{dw}$.

\section{Total phenolic content}

The total phenolic content was performed by the method as described by Baba and Malik (2015). Briefly, $3 \mathrm{~mL}$ of $S$. alata and $S$. tora leaf extracts were added with $0.5 \mathrm{~mL}$ of Follin Ciocalteu's Phenol reagent and let to sit for 3 minutes. Then, $2 \mathrm{~mL}$ of $20 \%$ (w/v) sodium carbonate were added and the mixture was allowed to stand in the dark for $60 \mathrm{~min}$. Following that, the absorbance was read at $650 \mathrm{~nm}$ by using a spectrophotometer (Libra S12, Biochrom, UK). The total phenolic content was calculated from the gallic acid (GAE) calibration curve and the results were expressed as $\mathrm{mg} \mathrm{GAE} / \mathrm{g} \mathrm{dw}$.

\section{Test for glycosides}

Two $\mathrm{mL}$ of acetic acid was added to $1 \mathrm{~mL}$ of leaf extracts and the solutions were then cooled in an ice bath at $4^{\circ} \mathrm{C} .1 \mathrm{~mL}$ of concentrated tetraoxosulphate (VI) acid $\left(\mathrm{H}_{2} \mathrm{SO}_{4}\right)$ was then added drop wise to the mixture. The formation of an oil layer on top of the solution indicates the presence of glycosides.

\section{Test for saponins}

Five drops of olive oil was added to $2 \mathrm{~mL}$ of leaf extracts and the mixtures were shaken vigorously. The formation of a stable emulsion indicates the presence of saponins.

\section{Test for tannins}

Two drops of $5 \% \mathrm{FeCl}_{3}$ was added to $1 \mathrm{~mL}$ of leaf extracts. The appearance of a dirty-green precipitate indicates the presence of tannins.

\section{Test for steroids}

One $\mathrm{mL}$ of concentrated tetraoxosulphate (vi) acid $\left(\mathrm{H}_{2} \mathrm{SO}_{4}\right)$ was added to $1 \mathrm{~mL}$ of leaf extracts. The red colouration indicates the presence of steroids.

\section{Test for terpenoids (Salkowski test)}

The leaf extracts in a final volume of $3 \mathrm{~mL}$ were mixed with $1 \mathrm{~mL}$ of chloroform and $1 \mathrm{~mL}$ concentration of $\mathrm{H}_{2} \mathrm{SO}_{4}$ to observe an intense red-brown coloration as an indicative of the presence of terpenoids.

\section{Antioxidant activity assay}

\section{DPPH scavenging activity}

A wavelength of $515 \mathrm{~nm}$ of spectrophotometer (Libra S12, Biochrom, UK) was set up to measure the radical scavenging capacity of leaves extracts. Ten-fold dilutions of both methanolic and ethanolic leaf extracts were added to $1.2 \mathrm{~mL}$ solution of DPPH $(100 \mu \mathrm{M}$ in methanol). A control solution was prepared by adding $0.2 \mathrm{~mL}$ methanol instead of the extract samples. After 30 minutes, the absorbance was measured. Determination of radical scavenging was calculated as follows (Equation 1):

DPPH activity $=\left(\right.$ Absorbance $_{\text {control }}$-Absorbance sample $\left._{\text {s }}\right) /$ Absorbance $_{\text {control }} \times 100$ Equation 1

\section{Ferric reducing-antioxidant power (FRAP) assay}

Modification of standard FRAP assay was performed as described by Rabeta and NurFaraniza (2013). $200 \mu \mathrm{L}$ extracted samples were mixed with $3 \mathrm{~mL}$ of FRAP reagent in test tubes and the solutions were mixed thoroughly by a vortex. Blank samples were prepared with both methanol and ethanol extraction samples. Both samples were incubated in water bath for 30 minutes at $37^{\circ} \mathrm{C}$.
Then, determination of sample absorbances at $593 \mathrm{~nm}$ against blank were conducted. The FRAP value was expressed as $\mu \mathrm{M}$ of ferrous equivalent Fe (II) per gram of dried sample.

\section{Antimicrobial tests}

\section{Determination of antimicrobial activity assay (agar well diffusion)}

A modified agar well diffusion technique as reported by Ehiowemwenguan $\boldsymbol{e t}$ al., (2014) was done to determine the antibacterial activity of leaf extracts against $S$. aureus, $S$. epidermidis and $P$. aeruginosa. All the strains were generously provided by Bioprocessing and Biomanufacturing Research Centre (BBRC), Universiti Putra Malaysia. Firstly, the glycerol stock of each bacterial strain was streaked into sterile Luria-Bertani (LB) agar for S. aureus and nutrient broth for S. epidermidis and P. aeruginosa and incubated in an oven for 24 hours at $37^{\circ} \mathrm{C}$. Then a loop of single colony of each strain was separately transferred into $5 \mathrm{~mL}$ of LB broth containing $S$. aureus, and $5 \mathrm{~mL}$ of nutrient broth for each of $S$. epidermidis and $P$. aeruginosa colony. Then, they were incubated for overnight at $37^{\circ} \mathrm{C}$. Then, nutrient agar plate was prepared by pouring $25 \mathrm{~mL}$ of nutrient agar into empty plates. $60 \mu \mathrm{L}$ of inoculum (optical density \pm 0.020 ) of each tested microorganism (equivalent to $10^{7} \mathrm{CFU} / \mathrm{mL}$ ) were added into $6 \mathrm{~mL}$ of LB agar for $S$. aureus and $6 \mathrm{~mL}$ nutrient agar media for $S$. epidermidis and $P$. aeruginosa. The colony forming unit (CFU/mL) of each strains was determined based on the method as described by Ming et al., (2016). Then, the warm LB and nutrient agar media were spread into agar plates. Four holes were made using backtips of micropipette tips onto the agars. $100 \mu \mathrm{L}$ of methanol and ethanol made as negative control and penicillin as a positive control. Then, the plates were incubated for overnight at $37^{\circ} \mathrm{C}$. After that, the inhibition zones observed on the agars were measured by a ruler for each isolated tested microorganisms.

\section{Determination of minimum inhibitory concentration (MIC)}

MIC of the $S$. alata and $S$. tora leaf extracts were determined according to the method as described by Bisht $\boldsymbol{e t}$ al., (2016). The Muller Hinton Broth (MHB) was prepared and autoclave sterilized at $121^{\circ} \mathrm{C}$ for 15 minutes (Hirayama, Hirayama Manufacturing Corporation, Japan). $1.0 \mathrm{~mL}$ of the prepared MHB broth was dispensed into test tubes labeled from 1 to 5 using sterile syringe and needle. $1.0 \mathrm{~mL}$ of the $60 \mathrm{mg} / \mathrm{mL}$ leaf extract solutions were separately dispensed into tube labeled 1 . After that, $1.0 \mathrm{~mL}$ of the solution was serially transferred into tube labeled 2 until tube labeled 5. Tube labeled 6 was filled with the sterile MHB solution to serve as a control for the sterility of the medium while tube labeled 7 contained sterile MHB solution and test organism as the control for the viability of the culture organisms. Test isolates (S. epidermidis, S. aureus, $P$. aeruginosa) were prepared in a sterile nutrient broth and were incubated in a shaker for overnight at $37^{\circ} \mathrm{C}, 200 \mathrm{rpm}$. Following incubation, $1.0 \mathrm{~mL}$ of each strain inoculum was transferred into each tube (tubes 1-7) except the tube 6 (control experiment) in which a new sterile broth was added. Leaf extracts were then added into each test tubes labeled 1 to 5 with the final concentration of each extract after dilution were $10.000,5.000,2.500,1.250$, and $0.625 \mathrm{mg} / \mathrm{mL}$, respectively. All the tubes were incubated at $37^{\circ} \mathrm{C}$ for 24 hours. Lastly, the growths of the organisms were examined. The lowest concentration (highest dilution) of the extract that produced no visible bacterial growth (no or low turbidity) and lowest optical density (at $650 \mathrm{~nm}$ ) for bacterial growth using a spectrophotometer (Libra S12, Biochrom, UK) when compared with the control tubes was regarded as MIC.

\section{Determination of minimum bactericidal concentration (MBC)}

Each test tube of MIC cultures (as described above) were then inoculated into the sterile Muller Hinton agar and incubated at $37^{\circ} \mathrm{C}$ for 24 hours. $\mathrm{MBC}$ is considered as the lowest concentration with no viable growth.

\section{RESULTS AND DISCUSSION}

\section{Phytochemical screening of $S$. alata and $S$. tora leaves}

The preliminary qualitative phytochemical components screening carried out for $S$. alata and $S$. tora leaf extracts revealed the presence of some bioactive components and secondary metabolites such as phenol, flavonoid, tannins, glycosides, steroids, saponins and terpenoids (Table 1). These secondary metabolites are reported to have many biological and therapeutic properties (Vishnu et al., 2013, Narender et al., 2012). 
Table 1 Phytochemical components of Senna alata and Senna tora leaves extracted with methanol and ethanol solvents (Drying method: Room temperature and Oven dried at $50^{\circ} \mathrm{C}$ )

\begin{tabular}{|c|c|c|c|c|c|c|c|c|}
\hline \multirow{3}{*}{$\begin{array}{l}\text { Leaves } \\
\text { Extracts }\end{array}$} & \multicolumn{4}{|c|}{ Senna alata } & \multicolumn{4}{|c|}{ Senna tora } \\
\hline & \multicolumn{2}{|c|}{$\begin{array}{c}\text { Room } \\
\text { Temperature }\end{array}$} & \multicolumn{2}{|c|}{$\begin{array}{c}\text { Oven Dried (at } \\
50^{\circ} \mathrm{C} \text { ) }\end{array}$} & \multicolumn{2}{|c|}{$\begin{array}{c}\text { Room } \\
\text { Temperature }\end{array}$} & \multicolumn{2}{|c|}{$\begin{array}{c}\text { Oven Dried (at } \\
50^{\circ} \mathrm{C} \text { ) }\end{array}$} \\
\hline & E & M & E & $\mathrm{M}$ & E & M & $\mathrm{E}$ & $\mathrm{M}$ \\
\hline Phenols & + & + & + & + & + & + & + & + \\
\hline Flavonoids & + & + & + & + & + & + & + & + \\
\hline Tannins & + & + & + & + & + & + & + & + \\
\hline Glycosides & + & + & + & + & + & + & + & + \\
\hline Steroids & + & + & + & + & + & + & + & + \\
\hline Saponins & + & + & + & + & + & + & + & + \\
\hline Terpenoids & + & + & + & + & + & + & + & + \\
\hline
\end{tabular}

Previously Moriyama et al., (2003) also reported that S. alata (synonym as Cassia alata) leaf contained several components of flavonoid glycosides. They found that the heat treated and sun-dried S. alata leaf extract contained a strong inhibitory effect on concanavalin A-induced histamine release, COX-1 and $\mathrm{COX}-2$, and 5-lipoxygenase activities while $\mathrm{K} 3 \mathrm{G}$ component that is the major flavonoid glycoside in this leaf showed a weak inhibitory effect. Besides leaf, the flower and seed coat extracts of $S$. alata are also positive for terpenoid, cardiac glycosides, steroids and terpenoids with an absence of alkaloids (Senthilkumar et al., 2013). Nonetheless, Uwangbaoje (2012) reported a contradictory result of the absent of steroid compounds in the $S$. alata leaf extract.

As reported by Supare and Mantil (2015) beside leaf, the seeds of $S$. tora (synonym as Cassia tora) are also positive for the appearances of phenolic compounds, glycoside, flavonoids, saponins and tannins. They also verified the larvicidal activity of the alcoholic S. tora seed extracts against Anopheles stephensi that specifies the plant potential to fight mosquito bites related diseases. Another study that was carried out by Sripriya (2014) confirmed the yielding of anthraquinones and carbohydrate compounds besides glycosides, steroids, flavonoids, and saponins in the $S$. tora leaf extracts. In the meantime, the present of terpenoids in the $S$. tora leaf extract (Table 1) was in contrary of the result obtained by Supare and Mantil (2015).

In general, based on this qualitative study, the drying methods (oven drying at $50^{\circ} \mathrm{C}$ and room temperature drying) and solvent (ethanol and methanol) extraction methods used have no influence on the phytochemical screening as a positive data was attained for all the tested samples. Nonetheless, a quantitative analysis is required to be conducted in order to confirm if there are any negative influences between these two parameters on the yields of the phytochemical constituents. Furthermore, Shanmugam et al., (2008) stated that, different solubility capacities for different phytochemical components can be affected by different solvents used and may also distinguished the activities of different sample extracts.

Quantitative evaluations were also conducted to determine the total phenolic and total flavonoids contents in the S. alata and S. tora leaf extracts. Flavonoids are among the major constituents in phenolic components found in various plants. These compounds are known for their function in protecting plants, fruits, and vegetables from oxidative damage and hence have been used as antioxidant agents by humans (Do et al., 2014).

As shown in Figure 1, the highest total phenolic contents in $S$. alata was the ethanolic $(95 \%(\mathrm{v} / \mathrm{v})$ ethanol) extract that was dried at room temperature which is $285.53 \mathrm{mg} \mathrm{GAE} / \mathrm{g} \mathrm{dw}$. Meanwhile the total phenolic content of methanolic extract $(80 \%(\mathrm{v} / \mathrm{v})$ methanol) of room temperature dried leaf was reduced to approximately half of this value. This observation shows the types of solvents used during the extraction method plays important roles in influencing the yields and perhaps the stability and activity of the phytochemical components in the plant extract. Different chemical characteristics and polarities of solvents may have influences on the solubility of antioxidant compounds presence in plant matrices (Turkmen et al., 2006). Besides types of solvents, the percentage of water content in the aqueous solvent may also plays an important role in the yield of total phenolic content. Do et al., (2014) found that the total phenolic content form Limnophila aromatica plant was higher when the plant was extracted with $75 \%$ aqueous methanol extract than that of $100 \%$ methanol extract. This observation was in contrast with the ethanol extract that showed higher total phenolic content in $100 \%$ ethanol compared to $75 \%$ aqueous ethanol. Hence, different percentages of ethanol and methanol for solvent extraction of $S$. alata and $S$. tora leaf extracts should also be studied to further understand their effects. Nonetheless, there was no apparent difference was observed for ethanolic and methanolic extracts of oven dried $S$. alata leaves for the total phenolic content. The highest total phenolic content for $S$. tora was recorded for the methanolic leaf extract that was dried at room temperature which is $385.37 \mathrm{mg} \mathrm{GAE} / \mathrm{g} \mathrm{dw}$, while a lower value was obtained for the ethanolic extract $(240.61 \mathrm{mg} \mathrm{GAE} / \mathrm{g} \mathrm{dw}$. A palpable difference in the total phenolic content was observed for $S$. tora ethanolic and methanolic leaf extracts that were oven dried at $50^{\circ} \mathrm{C}$. Nevertheless, it can be deduced that the phenolic constituents in both leaves preferred a moderate drying temperature such as room temperature compared to high temperature treatment such as $50^{\circ} \mathrm{C}$ or higher.

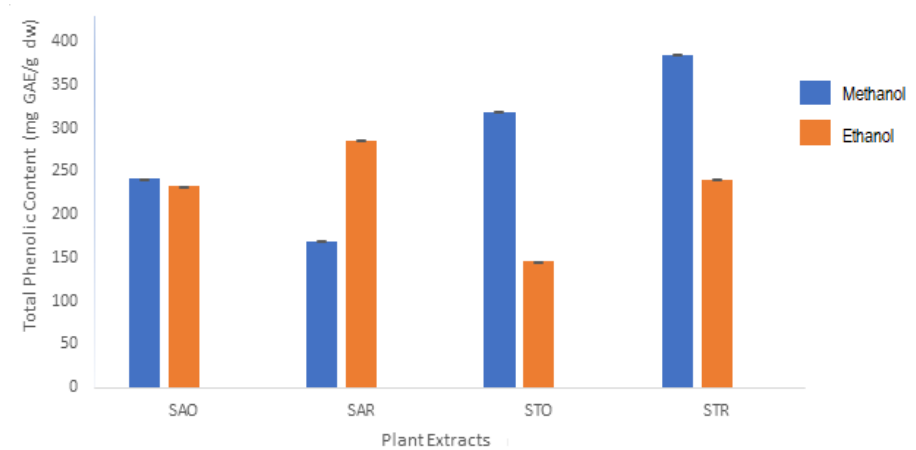

Figure 1 Total phenolic content (mg GAE/g dw) of Senna alata and Senna tora leaves extracted with methanol and ethanol solvents. $\mathrm{SAO}=S$. alata leaves dried at $50^{\circ} \mathrm{C}$ (oven dried), $\mathrm{SAR}=S$. alata leaves dried at room temperature, $\mathrm{STO}=S$. tora leaves dried at $50^{\circ} \mathrm{C}$ (oven dried), STR $=S$. tora leaves dried at room temperature. The error bar represents the standard deviation about the mean $(\mathrm{n}=3)$.

As displays in Figure 2, the highest total flavonoid contents in S. alata was the ethanolic extract that was dried at room temperature which is $447.42 \mathrm{mg}$ QE/g $\mathrm{dw}$. In comparison, this study showed a higher total flavonoids content compared to $43 \mathrm{mg} \mathrm{QE/g} \mathrm{as} \mathrm{previously} \mathrm{reported} \mathrm{by} \mathrm{Da}$ et al., (2014). A slightly lower value of $422 \mathrm{mg} \mathrm{QE} / \mathrm{g} \mathrm{dw}$ was measured for the ethanolic extract that was dried at $50^{\circ} \mathrm{C}$. Likewise, the similar pattern was observed for the $S$. tora leaf extracts. The highest value (345.43mg QE/ dw) was recorded for the ethanolic room temperature dried extract. The drying methods seemed to have a significant effect on $S$. tora leaves but the effect was not apparent for $S$. alata leaf extracts. The flavonoid constituents in the leaf of $S$. tora were found to be heat sensitive. In the meantime, ethanol was the best solvent for extracting the flavonoid components from both leaves. 


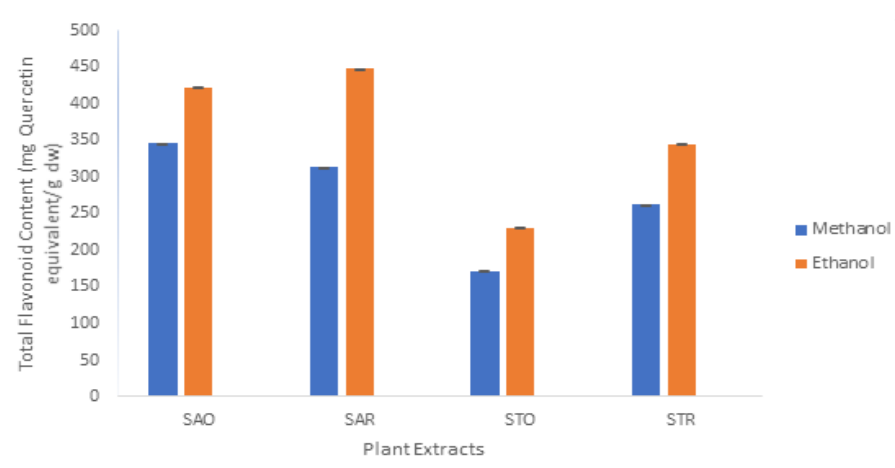

Figure 2 Total flavonoid contents (mg Quercetin equivalent/g dw) of Senna alata and Senna tora leaves extracted with methanol and ethanol solvents. SAO $=S$. alata leaves dried at $50^{\circ} \mathrm{C}$ (oven dried), $\mathrm{SAR}=S$. alata leaves dried at room temperature, $\mathrm{STO}=S$. tora leaves dried at $50^{\circ} \mathrm{C}$ (oven dried), $\mathrm{STR}=S$. tora leaves dried at room temperature. The error bar represents the standard deviation about the mean $(n=3)$.

\section{Antioxidant activity of S. alata and S. tora leaves}

The antioxidant capability and properties of $S$. alata and $S$. tora leaf extracts were quantified by DPPH radical scavenging activity and FRAP assays. The scavenging DPPH free radical methods is well known as fast, easy and cheapest method to measure antioxidant capacity of such as in food samples (Kirtikar and Basu, 1998). During the reaction, the stable organic free radical DPPH becomes paired off after reacting with free radical species and hence the absorbance is decreased (Harborne, 1984) and a noticeable discoloration from purple to yellow can be observed (Ghosh, 1998).

Figure 3 (A) shows the DPPH radical scavenging activity of $S$. alata and S. tora leaf extracts. For $S$. alata leaves, higher percentage of free scavenging activity was obtained for the methanolic extracts compared to the ethanolic extracts of both samples dried at room temperature and $50{ }^{\circ} \mathrm{C}$ (oven dried). While comparing the drying methods, a mild condition such as room temperature was preferable than the high temperature such as $50^{\circ} \mathrm{C}$ for optimum scavenging activity. Room temperature kept the freshness of the plant components without exposing it to any damaging effects by heat. In the meantime, no apparent differences were observed for the DPPH scavenging activity of $S$. tora leaf extracts regardless the drying conditions and solvent extract methods used as the percentages of all tested samples were in the range of $85-90 \%$.

In the meantime, the FRAP assay can be used to determine the capabilities of antioxidant agents in plants to reduce $\mathrm{Fe}^{3+}$ to $\mathrm{Fe}^{2+}$ in the presence of 2,4,6-tri(2pyridyl)-s-triazine (TPTZ), forming an intense blue $\mathrm{Fe}^{2+}$-TPTZ complex with an absorption maximum at $593 \mathrm{~nm}$ (Benzie and Strain, 1996). The absorbance value is directly proportional to the antioxidant content in the sample.

Figure 3 (B) shows the comparison between ethanolic and methanolic leaf extracts of $S$. alata and $S$. tora that were primarily dried with either in an oven at $50^{\circ} \mathrm{C}$ or at room temperature based on their FRAP activity. The FRAP values quantified in $S$. tora leaf extracts were much higher compared to the FRAP values of $S$. alata regardless the drying methods and solvents used for the extraction process. Despite the comparable DPPH radical scavenging percentage values were obtained for both leaf samples, a negative correlation was observed for FRAP values of $S$. alata. Among the tested samples, the highest FRAP value $(5614.88 \mu \mathrm{mol} / \mathrm{mg})$ was recorded by methanolic $S$. tora leaf extracts dried at room temperature. This is in accordance with the highest total phenolic content observed for the similar sample. Meanwhile the lowest FRAP value of 1016.13 $\mu \mathrm{mol} / \mathrm{mg}$ was obtained for ethanolic, room dried $S$. alata leaf extracts. Nonetheless, the FRAP values attained in this study is slightly higher compared to $996 \pm 22.16 \mu \mathrm{mol} / \mathrm{g}$ that was reported by Faboro et al., (2016) for S. alata leaf.
(A)
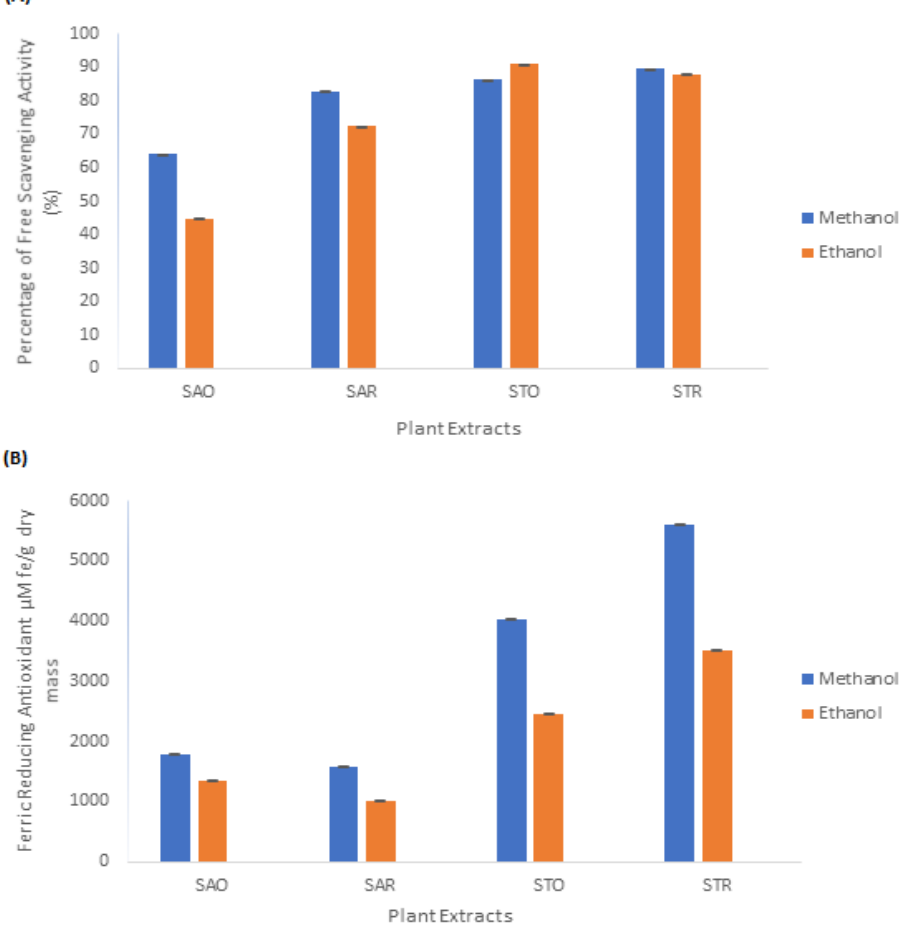

Figure 3 Percentage of free radical scavenging activity (A) and Ferric reducing antioxidant plasma ( $\mu \mathrm{mol} \mathrm{fe} / \mathrm{g}(\mathrm{B})$ of Senna alata and Senna tora leaves of methanol and ethanol extracts. $\mathrm{SAO}=S$. alata leaves dried at $50^{\circ} \mathrm{C}$ (oven dried), $\mathrm{SAR}=S$. alata leaves dried at room temperature, $\mathrm{STO}=S$. tora leaves dried at $50^{\circ} \mathrm{C}$ (oven dried), $\mathrm{STR}=S$. tora leaves dried at room temperature. The error bar represents the standard deviation about the mean $(n=3)$.

\section{Antimicrobial activity}

This study was aimed to evaluate the antimicrobial properties of the ethanolic and methnolic extracts of $S$. alata and $S$. tora leaves by examining the zone of inhibition by agar well diffusion method, minimum inhibitory concentration (MIC) as well as minimum bactericidal concentration (MBC) against skin microbial flora including $S$. aureus, S. epidermidis and P. aeruginosa.

\section{Agar well diffusion (zones of inhibition)}

Based on Table 2, the average measurement of each inhibition zones made from each alcoholic leaf extracts were taken from the ethanol and methanol of pure solvent (negative control). Both ethanolic and methanolic extracts of $S$. alata and $S$. tora leaf extracts showed no zones of inhibition in agar well diffusion assay for $S$. aureus. However, there were presence of inhibition zones for solvent extracts of $S$. alata and $S$. tora leaves for $P$. aeruginosa. While for $S$. epidermidis, zone of inhibition was only detected for $S$. tora leaf. These observations are quite contradicted with the previous work by Sripriya (2014) that reported on the methanolic extract of $S$. tora that was found to be active against all these three tested bacteria. In comparison, the inhibition zone measured for their $S$. alata leaf extract against $P$. aeruginosa is also much bigger than the inhibition zones exhibited by the $S$. tora leaf extracts obtained in this study.

Table 2 The antimicrobial activity of oven dried $\left(50^{\circ} \mathrm{C}\right)$ and room temperature dried of Senna alata and Senna tora leaf extracted using ethanol and methanol solvents against Staphylococcus aureus, Staphylococcus epidermidis and Pseudomonas aeruginosa.

\begin{tabular}{|c|c|c|c|c|c|c|c|c|}
\hline \multirow{4}{*}{ Test strain } & \multicolumn{4}{|c|}{ Senna alata leaf } & \multicolumn{4}{|c|}{ Senna tora leaf } \\
\hline & \multicolumn{2}{|c|}{ OD } & \multicolumn{2}{|c|}{ RT } & \multicolumn{2}{|c|}{ OD } & \multicolumn{2}{|c|}{ RT } \\
\hline & $\mathrm{M}$ & $\mathrm{E}$ & $\mathrm{M}$ & $\mathrm{E}$ & $\mathrm{M}$ & $\mathrm{E}$ & $\mathrm{M}$ & $\mathrm{E}$ \\
\hline & \multicolumn{8}{|c|}{ Mean clear zonal diameter $(\mathrm{mm})$} \\
\hline Staphylococcus aureus & - & - & - & - & - & - & - & - \\
\hline $\begin{array}{l}\text { Staphylococcus } \\
\text { epidermidis }\end{array}$ & - & - & - & - & 13.30 & 12.00 & 16.26 & 16.94 \\
\hline $\begin{array}{l}\text { Pseudomonas } \\
\text { aeruginosa }\end{array}$ & 1.48 & 1.15 & 1.59 & - & - & 1.00 & 1.35 & 1.68 \\
\hline
\end{tabular}

$O D=$ oven dried $\left(50^{\circ} \mathrm{C}\right)$ leaf extract; $R T=$ room temperature dried leaf extract; $E=$ ethanolic extract; $M=$ methanolic extract 
The oven dried $S$. alata leaf extracts showed zones of inhibition of $1.48 \mathrm{~mm}$ and $1.15 \mathrm{~mm}$ for methanolic and ethanolic extracts, respectively. On the other hand, the room temperature dried of $S$. alata leaf extracts showed a slightly bigger zone of inhibition which is $1.59 \mathrm{~mm}$ for the methanolic extracts but there was no zone of inhibition possess by the ethanolic extract. Previously, the methanolic extracts of $S$. alata leaf were reported to have inhibition zones of $3 \mathrm{~mm}$ and $5 \mathrm{~mm}$ for $P$. aeruginosa and $S$. aureus, respectively (Ehiowemwenguan $\boldsymbol{e t}$ al., 2014). No zone of inhibition was obtained for methanolic oven dried $S$. tora leaves extracts but $1.00 \mathrm{~mm}$ zone of inhibition was presence in the ethanolic extract. Meanwhile the ethanolic extract $S$. tora leaves dried at room temperature showed that the extract inhibited a much bigger zone than the methanolic extract $(1.68 \mathrm{~mm}$ and $1.35 \mathrm{~mm}$, respectively). Nevertheless there was a report that showed the methanolic extract of $S$. tora leaves possess $6 \mathrm{~mm}$ and $10 \mathrm{~mm}$ of inhibition zones for $P$. aeruginosa and $S$. aureus, respectively (Sripriya, 2014). According to Singh and Singh (2000) the yield of antimicrobial component in plant extract is commonly influenced by the non-polar or polar solvent used during the extraction process. Based on the types of solvents applied in this study, the result shows that the ethanolic extract exhibited much bigger zones than the methanolic extracts. The formation of zone of inhibitions by both $S$. alata and $S$. tora leaf extracts is shown in Figure 4.
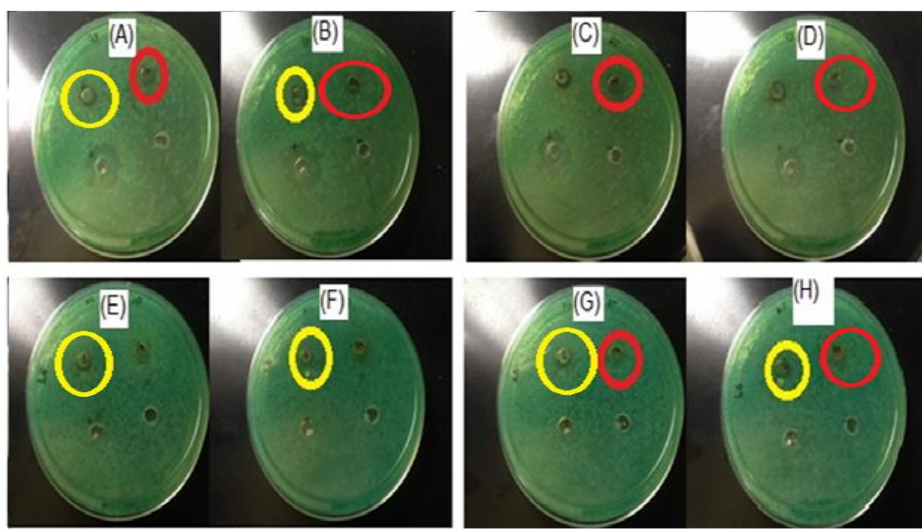

Figure 4 Inhibition zones produces by oven dried Senna alata leaves methanolic and ethanolic extraction of (A) methanol and (B) ethanol of pure solvent, room temperature dried Senna alata leaves methanolic and ethanolic extraction of (C) methanol and (D) ethanol pure solvent, Oven dried Senna tora leaves methanolic and ethanolic extraction of (E ) methanol and (F) ethanol of pure solvent, and room temperature dried Senna tora leaves methanolic and ethanolic extraction of $(\mathrm{G})$ methanol and $(\mathrm{H})$ ethanol of pure solvent towards isolated $P$. aeruginosa. Red circles $=$ methanolic leaves extracts and yellow circles $=$ ethanolic leaves extracts of the inhibition zones observed.

The antimicrobial activity exerted by $S$. tora leaf extracts was found to be approximately 12 to 16 times stronger for $S$. epidermidis compared to $P$. aeruginosa. Higher inhibition activities were achieved for both ethanolic (inhibition zone of $16.94 \mathrm{~mm}$ ) and methanolic (inhibition zone of $16.26 \mathrm{~mm}$ ) extracts of $S$. tora that were dried at room temperature than the ethanolic (inhibition zone of $12.00 \mathrm{~mm}$ ) and methanolic (inhibition zone of $13.30 \mathrm{~mm}$ ) extracts that were oven dried at $50^{\circ} \mathrm{C}$. The formation of zone of inhibition by both $S$. alata and S. tora leaf extracts is shown in Figure 5. The data from this study indicates that the temperature plays a role on the yielding and perhaps stability of the components responsible for the antimicrobial activity. According to Murugan et al., (2013) the antimicrobial activity that present in the plants is associated to the presence of phytochemical constituents such as flavonoids, steroids, saponins and tannins.

In general, the antimicrobial activity of plants cannot only be relying on the agar well diffusion method to conclusively justify any findings especially the negative result (i.e, no inhibition zone) observed. This is due to some disadvantages of the agar diffusion method in determining the antimicrobial activity since it may be affected by various factors such as agar type, salt concentration, incubation temperature and molecular size of the antimicrobial component (Eloff, 1998). Furthermore, this method also cannot be used to distinguish between bactericidal and bacteriostatic effects. Instead, minimum inhibitory concentration (MIC) and minimum bactericidal concentration (MBC) must be conducted to determine these effects (Mostafa et al., 2018).
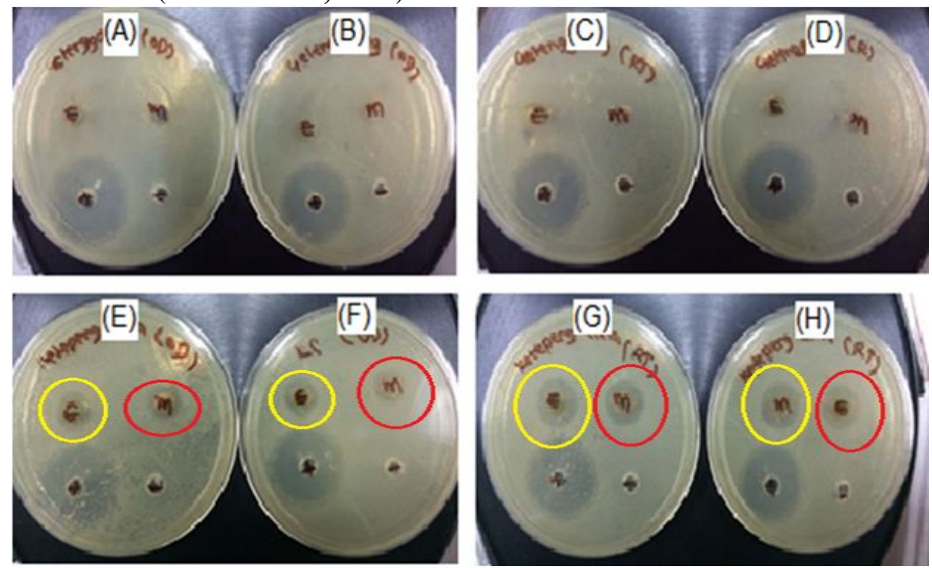

Figure 5 Inhibition zones produces by oven dried Senna alata leaves methanolic and ethanolic extraction of (A) methanol and (B) ethanol of pure solvent, room temperature dried $S$. alata leaves methanolic and ethanolic extraction of $(\mathrm{C})$ methanol and (D) ethanol pure solvent, Oven dried Senna tora leaves methanolic and ethanolic extraction of (E ) methanol and (F) ethanol of pure solvent, and room temperature dried $S$. tora leaves methanolic and ethanolic extraction of $(\mathrm{G})$ methanol and $(\mathrm{H})$ ethanol of pure solvent towards isolated S. epidermidis. Red circles $=$ methanolic leaves extracts and yellow circles $=$ ethanolic leaves extracts of the inhibition zones observed.

\section{Minimum inhibitory concentration (MIC)}

The reading of MIC for $S$. alata and $S$. tora leaf extracts has been taken by correlating it with the absorbance reading besides broth turbidity visualization. The absorbance of controls (control 1: sterile broth without test organism and control 2: test organisms grown in their respective media in absence of $S$. alata and $S$. tora leaf extracts) and each of serial dilution concentrations of $S$. alata and $S$. tora leaf extracts were taken to determine the lowest extract concentrations to inhibit the growth of tested microorganism. The tested microorganisms used were $S$. aureus, $S$. epidermidis and $P$. aeruginosa. The absorbance readings for control of broth containing tested $S$. aureus, $S$. epidermidis and $P$. aeruginosa (in absence of leaf extracts) were $1.230,2.810$ and 0.208 , respectively. The MIC values for tested microorganisms were taken by choosing the concentration that has absorbance reading below that of the control. Hence, the absorbance reading that are exceeded the control reading showed the presence of tested microorganism growth.

Table 3 The minimum inhibitory concentration (MIC) $(\mathrm{mg} / \mathrm{mL})$ of oven-dried Senna alata and Senna tora against Staphylococcus aureus, Staphylococcus epidermidis and Pseudomonas aeruginosa.

\begin{tabular}{|c|c|c|c|c|c|c|c|c|}
\hline \multirow{4}{*}{ Test organism } & \multicolumn{4}{|c|}{ Senna alata } & \multicolumn{4}{|c|}{ Senna tora } \\
\hline & \multicolumn{2}{|c|}{ OD } & \multicolumn{2}{|c|}{ RT } & \multicolumn{2}{|c|}{ OD } & \multicolumn{2}{|c|}{ RT } \\
\hline & $\mathrm{M}$ & $\mathrm{E}$ & $\mathrm{M}$ & $\mathrm{E}$ & $\mathrm{M}$ & $\mathrm{E}$ & $\mathrm{M}$ & $\mathrm{E}$ \\
\hline & \multicolumn{8}{|c|}{ MIC (mg/mL) } \\
\hline Staphyloccus aureus & 5 & 5 & 5 & 10 & 5 & 2.5 & 5 & 2.5 \\
\hline $\begin{array}{c}\text { Staphylococcus } \\
\text { epidermidis }\end{array}$ & 5 & 0.625 & 5 & 2.5 & 0.625 & 2.5 & 2.5 & 0.625 \\
\hline $\begin{array}{c}\text { Pseudomonas } \\
\text { aeruginosa }\end{array}$ & 0.625 & 0.625 & 0.625 & 0.625 & 0.625 & 0.625 & 0.625 & 0.625 \\
\hline
\end{tabular}

$O D=$ leaves dried using oven dried, $R T=$ leaves dried using room temperature, $M=$ methanol extracts of plant , $E=$ ethanol extracts of plan 
Based on Table 3, the methanolic extracts of $S$. alata leaf incubated with all tested organisms had MIC of $5 \mathrm{mg} / \mathrm{mL}$ for oven dried and room temperature dried of plant leaf, except for the $P$. aeruginosa with a much lower MIC value of $0.625 \mathrm{mg} / \mathrm{mL}$ for both types of leaf drying methods. While, the ethanolic extracts of $S$. alata leaf showed the MIC value of $0.625 \mathrm{mg} / \mathrm{mL}$ for oven dried leaf against $S$. epidermidis and $P$. aeruginosa but MIC of $5 \mathrm{mg} / \mathrm{mL}$ was observed for $S$. aureus. Meanwhile, the MIC obtained for ethanolic extracts of room temperature dried $S$. alata leaf for $S$. aureus, $S$. epidermidis and $P$. aeruginosa were of $10 \mathrm{mg} / \mathrm{mL}, 2.5 \mathrm{mg} / \mathrm{mL}$ and $0.625 \mathrm{mg} / \mathrm{mL}$, respectively. The presence of MIC value for $S$. alata leaf showing there is a weak inhibitory activity in the leaf extract for $S$. aureus despite none inhibition zone was observed in the agar well diffusion method.

Methanolic extracts of $S$. tora leaf had the lowest MIC values in the range of $0.625 \mathrm{mg} / \mathrm{mL}$ to $2.5 \mathrm{mg} / \mathrm{mL}$ for both type of leaf drying methods against $S$. epidermidis and $P$. aeruginosa with an exception for $S$. aureus with a MIC of 5 $\mathrm{mg} / \mathrm{mL}$. While, the ethanolic extracts of $S$. tora leaf have stronger inhibitory effect against all types of test organisms as the MIC values were in the range of $0.625 \mathrm{mg} / \mathrm{mL}$ to $2.5 \mathrm{mg} / \mathrm{mL}$. This showed that, ethanol is a more suitable solvent in order to get the lowest MIC values. In comparison, both of leaf extracts have the strongest inhibitory effect against $P$. aeruginosa as the MIC value is only $0.625 \mathrm{mg} / \mathrm{mL}$ compared to large variation on the MIC values attained for the other two tested organisms. Previously Saito et al., (2012) also reported that the $S$. alata leaf extract by reverse phase solid phase extraction method carried an antimicrobial activity against $P$. aeruginosa, S. epidermidis, $S$. aureus and Bacillus subtilis.

\section{Minimum bactericidal concentration (MBC)}

MBC was conducted to determine the lowest concentration of antimicrobial agent that is required to inhibit a specific microorganism. $\mathrm{MBC}$ is a complementary assay to MIC. In conducting the assay, a control of MBC had been prepared from the MIC assay performed earlier. The MBC values were selected by observation for the bacterial colony grown on the isolated agar plate. The plate with no growth and lowest concentration of MIC values was selected as MBC.

Table 4 shows that the MBC of $S$. alata and $S$. tora leaf extracts of different extraction solvents and different types of leaf drying methods for all three tested microorganisms (S. aureus, S. epidermidis and P. aeruginosa). The methanolic and ethanolic extracts of $S$. alata leaf against all tested microorganisms had MBCs of $10 \mathrm{mg} / \mathrm{mL}$ for both types of leaf drying methods, except for the ethanolic extracts against $P$. aeruginosa with a lower MBC of $5 \mathrm{mg} / \mathrm{mL}$.

In the meantime, the methanol extracts of $S$. tora leaf against all the tested microorganisms for both leaves drying methods shown a similar MBC values, which is $10 \mathrm{mg} / \mathrm{mL}$. However the ethanolic extracts of $S$. tora leaf shown that the samples possess the lowest MBC of $5 \mathrm{mg} / \mathrm{mL}$ for $P$. aeruginosa.

Table 4 The minimum bactericidal concentration (MBC) $(\mathrm{mg} / \mathrm{mL})$ of oven-dried Senna alata and Senna tora against Staphylococcus aureus, Staphylococcus epidermidis and Pseudomonas aeruginosa.

\begin{tabular}{|c|c|c|c|c|c|c|c|c|}
\hline \multirow{4}{*}{ Test organism } & \multicolumn{4}{|c|}{ Senna alata } & \multicolumn{4}{|c|}{ Senna tora } \\
\hline & \multicolumn{2}{|l|}{ OD } & \multicolumn{2}{|l|}{ RT } & \multicolumn{2}{|c|}{ OD } & \multicolumn{2}{|l|}{ RT } \\
\hline & $\mathrm{M}$ & $\mathrm{E}$ & $\mathrm{M}$ & $\mathrm{E}$ & $\mathrm{M}$ & $\mathrm{E}$ & $\mathrm{M}$ & $\mathrm{E}$ \\
\hline & \multicolumn{8}{|c|}{ MBC $(\mathrm{mg} / \mathrm{mL})$} \\
\hline Staphyloccus aureus & 10 & 10 & 10 & 10 & 10 & 10 & 10 & 10 \\
\hline $\begin{array}{l}\text { Staphylococcus } \\
\text { epidermidis }\end{array}$ & 10 & 10 & 10 & 10 & 10 & 10 & 10 & 5 \\
\hline $\begin{array}{l}\text { Pseudomonas } \\
\text { aeruginosa }\end{array}$ & 10 & 10 & 10 & 5 & 10 & 5 & 10 & 5 \\
\hline
\end{tabular}

$O D=$ leaves dried using oven dried, $R T=$ leaves dried using room temperature, $M=$ methanol extracts of plant, $E=$ ethanol extracts of plant.

\section{CONCLUSION}

S. alata and $S$. tora leaves were found to be positive for the presence of phenols, flavonoids, tannis, glycosides, steroids, saponins and terpenoids. The quantitative assays on total phenolic contents revealed the highest values were obtained for room temperature dried leaves of ethanolic extract for $S$. alata and methanolic extract for $S$. tora. While the highest total flavonoids content were recorded for extracts of room temperature-dried leaves for both $S$. alata and $S$. tora ethanolic. For DPPH radical scavenging activity, the maximum activity for S. alata samples was observed for methanolic extract of room temperature-dried leaves $(80 \%)$ while for S. tora all the samples showed approximately the same values in the range of $85-90 \%$. In comparison, $S$. alata leaves expressed a much lower FRAP values than the $S$. tora leaves extracts. $S$. alata leaf extracts showed an inhibition against $P$. aeruginosa, while $S$. tora leaf extracts were positive against $P$. aeruginosa and $S$. epidermidis. The MIC and MBC tests demonstrated that $S$. alata and S. tora leaves extracts expressed the best MIC and MBC against $P$. aeruginosa followed by $S$. epidermidis and $S$. aureus.

Declaration of conflict of interest: The authors have declared no conflict of interest.

Acknowledgments: This work was supported by the grant 9559400 (GP-IPS) from Universiti Putra Malaysia.

\section{REFERENCES}

ABO, K.A., FRED-JAIYESIMI, A.A., JAIYESIMI, A.E.A. (2008). Ethnobotanical studies of medicinal plants used in the management of diabetes mellitus in South Western Nigeria. Journal of Ethnopharmacology, 115(1), 6771. http://dx.doi.org/10.1016/j.jep.2007.09.005
ADELOWO, F., OLADEJI, O. (2017). An overview of the phytochemical analysis of bioactive compounds in Senna alata. Advances in Biochemistry, 5(5), 102-109. https://doi.org/10.11648/j.ab.20170505.14

BABA, S.A., MALIK, A.S. (2015). Determination of total phenolic and flavonoid content, anti-microbial and antioxidant activity of a root extract of Arisaema jacquemonti Blume. Journal of Taibah University for Science, 9(4), 449-454. https://doi.org/10.1016/j.jtusci.2014.11.001

BENZIE, I.F., STRAIN, J.J. (1996). The ferric reducing ability of plasma (FRAP) as a measure of "antioxidant power": the FRAP assay. Analytical Biochemistry, 239(1), 70-76. https://doi.org/10.1006/abio.1996.0292

BISHT, R., SHARMA, D., AGRAWAL, P.K. (2016). Antagonistic and antibacterial activity of endophytic fungi isolated from needle of Cupressus torulosa D. Don. Asian Journal of Pharmaceutical and Clinical Research, 9, 282-288.

COGEN A.L, NIZET V., GALLO R.L. (2008). Skin microbiota: a source of disease or defence?. British Journal of Dermatology, 158(3), 442-455. https://doi.org/10.1111/j.1365-2133.2008.08437.x

COWAN, M.M. (1999). Plant products as antimicrobial agents. Clinical Microbiology Reviews, 12, 564-582.

DA, O., TRAORE, M., YERBANGA, R.S., KOAMA, B., OUEDRAOGO, N., TAMBOURA, S. OUEDRAOGO, J. B. (2014). Antiplasmodial and antioxidant activities of saye: A traditional herbal remedy for malaria. American Journal of Biochemistry and Molecular Biology, 4(4), 155-166. https://doi.org/10.3923/ajbmb.2014.155.166

DAWID, R. (2013). Medicinal plants used in treatment of inflammatory skin diseases. Postepy Dermatol Alergol, 30(3), 170-177.

DO, Q.D., ANGKAWIJAYA, A.E., TRAN-NGUYEN, P.L., HUYNH, L.H., SOETAREDJO, F.E., ISMADJI, S., JU, Y-H. (2014). Effect of extraction solvent on total phenol content, total falvonoid content, and antioxidant activity of Limnophila aromatica. Journal of Food Drug and Analysis, 22(3), 296-302. https://doi.org/10.1016/j.jfda.2013.11.001 
EHIOWEMWENGUAN, G., INETIANBOR, J.E., YAKUBU, J.M. (2014). Antimicrobial qualities of Senna Alata. IOSR Journal of Pharmacy and Biological Sciences, 9(2), 47-52.

ELOFF, J.N. (1998). A sensitive and quick microplate method to determine the minimal inhibitory concentration of plant extracts for bacteria. Planta Medica, 64(8), 711-713. https://doi.org/10.1055/s-2006-957563

FABORO, E.O., WITCHITNITHAD, W., FADARE, O.A., AKINPELU, D.A., OBAFEMI, C.A. (2016). Antibacterial and antioxidant activities and phytochemical screening of aqueous methanol extracts of eight Nigerian medicinal and aromatic plants. Journal of Pharmacy Research, 10(7), 523-532.

GHOSH, M. N. (1998). Fundamentals of Experimental Pharmacology, 2nd Edn., Scientific Book Agency, Calcutta, p174-179.

HARBORNE, J. B. (1984). Phytochemical Methods. London, UK: Chapman and hall, 166-226.

HE, Z., TAN, Z.S., ABBASILIASI, S., LAI, O.M., TAM, Y.J., HALIM, M., ARIFF, A.B. (2015). Primary recovery of miraculin from miracle fruit, Synsepalum dulcificum by AOT reverse micellar system. LWT-Food Science and Technology, 64(2), 1243-1250. https://doi.org/10.1016/j.lwt.2015.07.045

IGOLI, J.O., OGAJI, O.G., IGOLI, N.P. TOR-ANYIIN, T.A. (2005). Traditional medicinal practices among the Igede people of Nigeria (part II). African Journal of Traditional, Complimentary and Alternative Medicines, 2(2), 134-152.

IQBAL, E., ABU SALIM, K., LIM, L.B.L. (2015). Antioxidant activities of bark and leaf extracts of Goniothalamus velutinus (Airy Shaw) from Brunei Darussalam. Journal of King Saud University - Science, 27(3), 224-232. https://doi.org/10.1016/j.j.jsus.2015.02.003

JAIN, S., PATIL, U.K. (2010). Phytochemical and pharmacological profile of Cassia tora Linn. - An overview. Indian Journal of Natural Products and Resources, 1(4), 430-437.

KIRTIKAR, K.R., BASU B.D. (1998). Indian Medicinal Plants, International Book Distributor, Dehra Dun, 2nd Edn, Vol. II, p878

LAI, P.K., ROY, J. (2004). Antimicrobial and chemopreventive properties of herbs and spices. Current Medical Chemistry, 11(11), 1451-1460. https://doi.org/10.2174/0929867043365107

MING, L.C., HALIM, M., RAHIM, RA., WAN, HY., ARIFF, A.B. (2016). Strategies in fed-batch cultivation on the production performance of Lactobacillus salivarius I 24 viable cells. Food Science and Biotechnology, 25(5), 1393-1398. https://doi.org/10.1007/s10068-016-0217-1

MORIYAMA, H., IIZUKA, T., NAGAI, M., MIYATAKA, H., SATOH, T. (2003). Antiinflammatory activity of heat-treated Cassia alata leaf extract and its flavonoid glycoside. Yakugaku Zasshi, 123(7), 607-611. https://doi.org/10.1248/yakushi.123.607 MOSTAFA, A.A., AL-ASKAR, A.A., ALMAARY, K.S., DAWOUD T.M., SHOLKAMY, E.N., BAKRI, M.M. (2018). Antimicrobial activity of some plant extracts against bacterial strains causing food poisoning diseases. Saudi Journal of Biological Sciences, 25(2), 361-366. https://doi.org/10.1016/j.s.jbs.2017.02.004

MURUGAN, S.B., DEEPIKA, R., RESHMA, A., SATHISHKUMAR, R. (2013). Antioxidant perspective of selected medicinal herbs in India: A probable source for natural antioxidants. Journal of Pharmacy Research, 7, 271-274.

NAIK, S., BOULADOUX, N., LINEHAN, J.L., HAN, S.J, HARRISON, O.J., WILHELM, C., CONLAN, S., HIMMELFARB, S., BYRD, A.L., DEMING, C., et al. (2015). Commensal-dendritic-cell interaction specifies a unique protective skin immune signature. Nature, 520(7545), 104-108. https://doi.org/10.1038/nature14052

NARENDER, P.D., GANGA, R., SAMBASIVA, E., MALLIKARJUNA. T., VASSILEIA, J.S. (2012). Quantification of phytochemical constituents and in vitro antioxidant activity of Mesua ferrea leaves. Asian Pacific Journal of Tropical Biomedicine, 2(2), 539-542. $\quad$ https://doi.org/10.1016/S22211691(12)60269-X

OLUDURO, A. OMOBOYE, O. (2010). In Vitro antibacterial potentials and synergistic effect of South-Western Nigerian plant parts used in Folklore remedy for Salmonella typhi infection. Nature and Science, 8(9), 52-59.

PENGSUPARP, T., CAI, L., CONSTANT, H., FONG, H.H., LIN, L.Z., KINGHORN, A.D., PEZZUTO, J.M., CORDELL, G.A., INGOLFSDOTTIR, K., WAGNER, H. (1995). Mechanistic evaluation of new plant-derived compounds that inhibit HIV-1 reverse transcriptase. Journal of Natural Products, 58(7), 1024-1031. https://doi.org/10.1021/np50121a006

RABETA, M.S., LIN, S.P. (2015). Effects of different drying methods on the antioxidant activities of leaves and berries of Cayratia trifolia. Sains Malaysiana, 44(2), 275-280.

RABETA, M.S., NUR FARANIZA, R. (2013). Total phenolic content and ferric reducing antioxidant power of the leaves and fruits of Garcinia atrovirdis and Cynometra cauliflora. International Food Research Journal, 20(4), 1691-1696. SAITO, S.T., TRENTIN, D.S., MACEDO, A.J., PUNGARTNIK C., GOSMANN G., SILVEIRA J.D., GUECHEVA T.N., HENRIQUES J.A.,
BRENDEL M. (2012). Bioguided fractionation shows Cassia alata extract to Inhibit Staphylococcus epidermidis and Pseudomonas aeruginosa Growth and Biofilm Formation. Evidence-Based Complementary and Alternaternative Medicine, 2012, 867103. http://dx.doi.org/10.1155/2012/867103

SENTHILKUMAR, R.P., MALAYALAM, V., SINDHUJA, S. (2013). Phytochemical screening and antibacterial evaluation of the leaf, flower and seed coat extracts of Cassia alata L. Journal of Chemical and Pharmaceutical Research, 5(11), 740-744.

SHANMUGAM, K., HOLMQUIST, L., STEELE, M., STUCHBURY, G. BERBAUM, K., SCHULZ, O., BENAVENTE GARC'IA, O., CASTILLO, J. BURNELL, J., GARCIA RIVAS, V., DOBSON, G. M“UNCH, G. (2008). Plantderived polyphenols attenuate lipopolysaccharide-induced nitric oxide and tumour necrosis factor production in murine microglia intoxification in rats. Journal of Ethnopharmacology, 66, 355-361.

SINGH, I. SINGH, V. P. (2000). Antifungal properties of aqueous and organic solution extracts of seed plants against Aspergillus flavus and A.niger Phytomorphology: An International Journal of Plant Morphology, 50(2), 151157.

SRIPRIYA, D. (2014). Antimicrobial activity of Cassia tora Lin (leaf) against some human pathogenic microbes. Biolife, 2(3), 747-752.

SUPARE, S., MANTIL, P. (2015). Estimation of phytochemical components from Cassia tora and to study its larvicidal activity. International Journal of Pharmaceutical Science Invention, 4,11-16.

TURKMEN, N., SARI, F., VELIOGLU, Y.S. (2006). Effects of extraction solvents on concentration and antioxidant activity of black and black mate tea polyphenols determined by ferrous tartate and Folin-Ciocalteu methods. Food Chemistry, 99(4),835-841. https://doi.org/10.1016/j.foodchem.2005.08.034

UWANGBAOJE, L.O. (2012). The mineral and phytochemical analysis of the leaves of Senna alata and Cajanus cajan and their medicinal value. International Journal of Biology, Pharmacy and Allied Sciences, 1, 1-11.

VISHNU, R., NISHA, R., JAMUNA, S., PAULSAMY, S. (2013). Quantification of total phenolics and flavonoids and evaluation of in vitro antioxidant properties of methanolic leaf extract of Tarenna asiatica - an endemic medicinal plant species of Maruthamali hills, Western Ghats, Tami Nadu. Journal of Research in Plant Sciences, 2, 196-204. 